\title{
Health coaching as a lifestyle medicine process in primary care
}

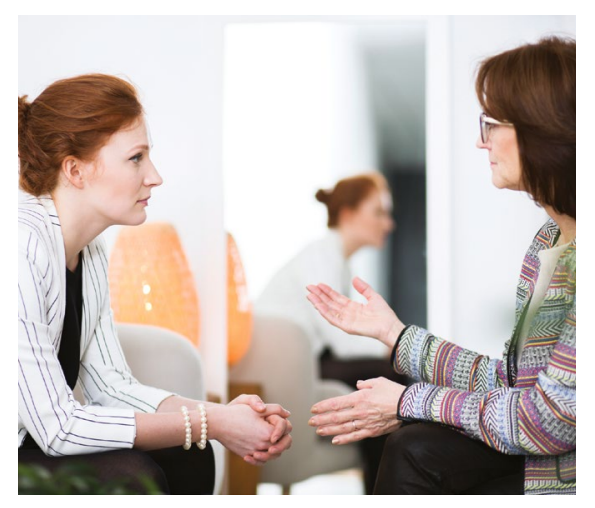

CPD

Shivaun Conn, Sharon Curtain

\section{Background \\ Lifestyle medicine is a relatively new approach to managing lifestyle-related disease. Health coaching is an integral part of lifestyle medicine that can be used to facilitate behaviour change in key lifestyle areas.}

\section{Objective}

The aim of this article is to familiarise general practitioners with the emerging discipline of health coaching and show its effectiveness in primary care.

\section{Discussion}

The recognition that the traditional healthcare approach is not fully effective at supporting health behaviour change in an era of chronic diseases has led to the emergence and growth of a new approach to the prevention and treatment of lifestyle-related diseases the practice of health coaching.
ONE IN TWO AUSTRALIANS has at least one chronic disease, ${ }^{1}$ with preventable lifestyle factors (eg poor diet and nutrition, physical inactivity, smoking and alcohol overconsumption) known to account for at least $70 \%$ of the total healthcare burden. ${ }^{2}$ General practitioners (GPs), as the first and most consistent point of contact with patients, play a vital part in prevention, early intervention and management of lifestyle-related disease. Traditionally, the health professional's role in assisting patients to change their unhealthy habits and adopt healthier lifelong behaviours has been to educate, persuade and prescribe actions to reduce ill health.

The World Health Organization states that 'simply giving information to patients is unlikely to change behaviour; health care providers must understand the psychological principles that underlie self-management training and comprehend that motivating patients requires more than imparting brief information to the patient'. ${ }^{3}$ Long-term health behaviour change requires a different approach to acute disease management. To achieve sustainable health behaviours and outcomes, patients need to be supported in behaviour change techniques that promote self-efficacy, self-determination and self-responsibility.

\section{What is health coaching?}

Health coaching is the practice of health education and health promotion within a coaching context to enhance the well-being of individuals and to facilitate the achievement of their health-related goals. ${ }^{4}$

Health coaching incorporates evidencebased health behaviour change interventions and techniques from behavioural medicine research literature, positive psychology, health and coaching psychology, and athletic and performance coaching. It can be used in health promotion, prevention, early intervention, treatment and management of chronic conditions such as in lifestyle medicine. Using the Transtheoretical Model, ${ }^{5}$ health coaching identifies the patient's stage of change, guiding clients to take stage-appropriate actions to increase confidence or importance and therefore moving clients towards readiness.

Health coaching supports patients to build self-determination - the process by which a person controls their own life - and self-efficacy - the belief that one has the capability to initiate and sustain a desired behaviour. Motivation is generated by supporting patients to evoke their own compelling reasons for change and articulate a clear vision of their health goals. Deci and Ryan's self-determination theory of motivation ${ }^{6}$ is applied through fostering 
autonomy, competence and relatedness, and linking clients to intrinsic motivators.

Once the patient is ready to change, they are encouraged to have a curious and flexible mindset of trial and correction, learning, growth and compassion as they are guided towards their goals while connecting to their values and vision. The health coaching process encourages self-reflection, self-awareness, self-regulation and positivity. Patients are supported to build confidence, focusing on strengths as they learn from past failures and successes to overcome barriers and increase facilitators for change. Behaviour change is more likely to be maintained when goals are self-determined, as patients are both motivated to take action and are invested in the result.

\section{Evidence to support health coaching}

Systematic reviews of health coaching in comparison to traditional care (Table 1)

have found health coaching to:

- significantly improve patients' physiological, behavioural, psychological and social outcomes ${ }^{7}$

- significantly improve one or more of the behaviours of nutrition, physical activity, weight management or medication adherence ${ }^{8}$

- improve glycaemic control and reduce glycated haemoglobin for patients with type 2 diabetes ${ }^{9,10}$

- improve medication adherence ${ }^{11}$

- assist with weight loss and increase the levels of motivation and personal satisfaction $^{12}$

- be an effective strategy to promote reductions in energy intake, body weight and body mass index ${ }^{13,14}$

- improve physical activity. ${ }^{15}$

These findings are in addition to a number of studies that show the efficacy of motivational interviewing in smoking cessation, alcohol reduction and other behaviour change. ${ }^{16}$

\section{Can primary care benefit from} the practice of health coaching? Incorporation of the health coaching framework into primary care can improve patient outcomes. Health coaching increases the chance of patients implementing and maintaining health behaviour change.

The benefits of health coaching are not only limited to patient outcomes, but also result in:

- enhanced practitioner job satisfaction

- enhanced patient satisfaction with services and outcomes

- improved consultation efficiency and effectiveness

- decreased reliance on the medical system by patients who learn self-management skills

- enhanced multidisciplinary professional collaboration.

\section{Integrating health coaching into practice}

Integrating health coaching into practice requires an understanding of a patient's readiness to change and of the support patients need to change (Figure 1). This can be achieved by asking patient-centred questions.

Patient-centred questions can help ascertain the importance of change to a patient, build confidence, generate insights and momentum, and ensure goals are determined by the patient.

Consider an overweight patient with pre-diabetes. Weight loss has been identified as an important goal for this patient.

\section{First, assess readiness to change}

Readiness is influenced by how important the behaviour is to the patient and how confident they feel about changing their behaviour. Using rating questions is an effective way to gauge confidence and importance.

Ask your patient, 'Given everything going on in your life, how important is it to you to lose weight?' The patient is asked to respond on a scale of $0-10$, with 0 meaning 'not important' and 10 meaning 'very important'. If your patient gives you a low score, such as 4 , they are not ready to change. Attempting to educate or persuade them, such as by providing advice about how to lose weight or information about consequences, is an ineffective strategy.

\section{Find out the reasons they want to change}

Ask, 'Why did you choose 4 and not 2?' (ie why not a lower number?). The patient will describe why change is important to them, and you can reflect these motivational hooks back to the patient to strengthen their decision to change. For example, they might say, 'I chose a 4 because I know that losing weight can help my diabetes'. That allows you to ask them to tell you more about how it would benefit them, and they will begin to talk themselves into change.

\section{Find out about the barriers}

Asking, 'Why did you choose a 4 and not an 8?' can reveal the barriers and reasons why change is not a priority. The patient may have low confidence due to
Table 1. Comparisons between a traditional clinical approach and coaching approach in primary care

\begin{tabular}{ll}
\hline Traditional approach & Coaching approach \\
\hline Practitioner is the health expert & $\begin{array}{l}\text { Patient is respected as the expert in their } \\
\text { own life }\end{array}$ \\
\hline Practitioner provides advice and solutions & $\begin{array}{l}\text { Practitioner offers information on the basis of } \\
\text { What the patient identifies as needed }\end{array}$ \\
\hline Practitioner decides the health priority & $\begin{array}{l}\text { Patient chooses the health goals, strategies } \\
\text { and targets }\end{array}$ \\
\hline Practitioner focus is on why the patient has & $\begin{array}{l}\text { Practitioner looks for positives and } \\
\text { affirms client }\end{array}$ \\
not made the required changes & $\begin{array}{l}\text { Practitioner identifies client readiness and } \\
\text { offers strategies to increase confidence and } \\
\text { Practitioner assumes client is ready }\end{array}$ \\
to change & importance. \\
\hline
\end{tabular}


failed attempts to lose weight in the past, knowledge gaps or competing priorities.

The practitioner can ask:

- 'What information would you like to know?'

- 'What skills and support do you need?'

- 'If you were going to change, how would you do it?'

- 'What is already working and/or what have you considered changing?'

The practitioner can then provide missing information, challenge beliefs or explore what is possible.

\section{Patient-centred goal setting}

Behaviour change is more likely to be maintained when goals are self-determined. The practitioner can ask:

- 'What are you willing to try?'

- 'What feels achievable?'

- 'What do you want to achieve?' While these strategies are just the tip of the behaviour-change iceberg, they can begin to help patients build the self-determination and self-efficacy that leads to sustainable behaviour change.

\section{Modes of delivery}

Health coaching may be integrated into primary care practice to improve effectiveness and efficiency of consultations.

Incorporating health coaching into primary care can be done in a number of ways:

- GPs can incorporate health coaching into their consultations

- GPs can refer patients to practice nurses and/or allied health professionals who are trained as health coaches

- GPs may refer to a qualified/accredited health coach who may consult within or outside a practice via face-to-face delivery, telephone or Zoom/Skype.

\section{Health coaching training}

The increasing popularity of health coaching has resulted in the emergence of various training options. Choices range from training in individual behaviour change disciplines - such as cognitive behavioural therapy, positivity psychology and motivational interviewing - to short courses in health coaching, a number of online-based courses and postgraduate qualifications in coaching psychology. The need for credible training qualifications that focus on Australian guidelines and standards has resulted in the options for health coach training expanding from short courses to an Australian diploma due to launch at the beginning of 2020 .

The level of health coaching training needed by an individual will depend on pre-existing training, skills, knowledge and experience. Practising health coaching skills on an ongoing basis and participating in continuing professional development is also essential.

\section{Summary}

Prevention and management of chronic health conditions is an area of growing demand. Integrating health coaching into primary care can significantly improve patients' physiological, behavioural, psychological and social outcomes, as well as lead to higher rates of satisfaction for both patient and clinician.

\section{Key points}

- Chronic diseases call for different approaches to management at the clinical level.

- Health coaching is a relatively new approach to modifying behaviours associated with the development of ill health.
- Health knowledge

- Relationship-building skills

- Empathy

- Listening skills

- Problem-solving skills

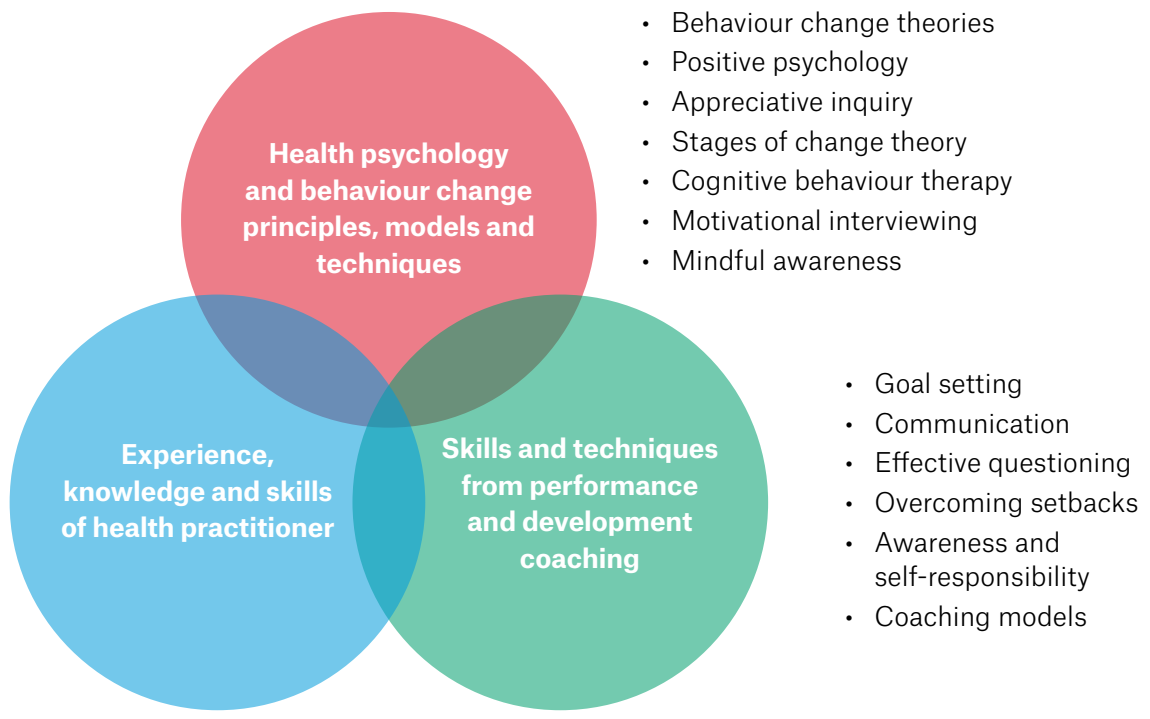

Figure 1. A number of skills and models can be integrated into general practice to adopt a health coaching approach. 
- Health coaching uses health behaviour change theories to build motivation and promote self-determination and self-efficacy.

- Health coaching acknowledges the patient's stage of change, and increases importance and confidence to increase readiness to change.

\section{Recommended resources}

- Miller WR, Rollnick S. Applications of motivational interviewing. Motivational interviewing: Helping people change 3rd edn. New York, NY: Guilford Press, 2013.

- AMA STEPS forward - Health coaching: Help patients take charge of their health*

- BMJ Learning - Motivational interviewing in brief consultations*

- The ineffective physician: Non-motivational approach ${ }^{*}$

- The effective physician: Motivational interviewing demonstration*

\section{${ }^{\star}$ Links to these resources are available online.}

\section{Authors}

Shivaun Conn BSc (Nutrition) (Hons), Accredited Practising Dietitian (APD), Accredited Nutritionist (AN), Health Coach, Director, Discovery Health Coaching, NSW; Vice President, Australasian Society of Lifestyle Medicine, Vic. shivaun@discoveryhealthcoaching.com
Sharon Curtain BSc, MDiet, Dietitian, Nutritionist, Health Coach, Director, Campaign Healthy, Vic; author and co-creator, Diploma of Health Coaching, Vic Competing interests: S Conn is a Board Member of the Australasian Society of Lifestyle Medicine (voluntary unpaid position). S Curtain is the co-author and co-creator of the Victoria University Polytechnic's Health Coaching Diploma course.

Funding: None.

Provenance and peer review: Commissioned, externally peer reviewed.

\section{References}

1. Australian Institute of Health and Welfare. Australia's health 2018. Cat. no. AUS 221. Canberra: AlHW, 2018.

2. Australian Institute of Health and Welfare. Australia's health 2016. Cat. no. AUS 199. Canberra: AlHW, 2016.

3. World Health Organization. Adherence to long-term therapies: Evidence for action. Geneva: WHO, 2003.

4. Palmer S, Tubbs I, Whybrow W. Health coaching to facilitate the promotion of healthy behaviour and achievement of health-related goals. Int J Health Promot Educ 2003;41(3):91-93. doi: 10.1080/14635240.2003.10806231.

5. Prochaska JO, DiClemente CC. The transtheoretical approach: Towards a systematic eclectic framework. Homewood, IL: Dow Jones Irwin, 1984.

6. Deci EL, Ryan RM. Intrinsic motivation and selfdetermination in human behavior. New York, NY: Plenum, 1985.

7. Kivelä K, Elo S, Kyngäs H, Kääriäinen M. The effects of health coaching on adult patients with chronic diseases: A systematic review. Patient Educ Couns 2014;97(2):147-57. doi: 10.1016/j. pec.2014.07.026.

8. Olsen JM, Nesbitt BJ. Health coaching to improve healthy lifestyle behaviors: An integrative review. Am J Health Promot 2010;25(1):e1-e12. doi: 10.4278/ajhp.090313LIT-101.
9. Wayne N, Perez DF, Kaplan DM, Ritvo P. Health coaching reduces $\mathrm{HbA} 1 \mathrm{c}$ in type 2 diabetic patients from a lower-socioeconomic status community: A randomized trial. J Med Internet Res 2015;17(10):e244. doi: 10.2196/jmir.4871.

10. Thom DH, Ghorob A, Hessler D, De Vore D, Chen E, Bodenheimer TA. Impact of peer health coaching on glycemic control in lowincome patients with diabetes: A randomized controlled trial. Ann Fam Med 2013;11(12):137-44. doi: 10.1370/afm.1443.

11. Thom DH, Willard-Grace R, Hessler D, et al. The impact of health coaching on medication adherence in patients with poorly controlled diabetes, hypertension, and/or hyperlipidemia: A randomized control trial. J Am Board Fam Med 2015;28(1):38-45. doi: 10.3122/ jabfm.2015.01.140317.

12. Muñoz Obino KF, Aguiar Pereira $C$ Caron-Lienert RS. Coaching and barriers to weight loss: An integrative review. Diabetes Metab Syndr Obes 201710:1-11. doi: 10.2147/ DMSO.S113874.

13. Tucker LA, Cook AJ, Nokes NR, Adams TB. Telephone-based diet and exercise coaching and a weight-loss supplement result in weight and fat loss in 120 men and women. Am J Health Promot 2008;23(2):121-29. doi: 10.4278/ajhp.07051646.

14. Shahnazari M, Ceresa C, Foley S, Fong A, Zidaru E, Moody S. Nutrition-focused wellness coaching promotes a reduction in body weight in overweight US veterans. J Acad Nutr Diet 2013;113(7):928-35. doi: 10.1016/j.jand.2013.04.001.

15. Barrett S, Begg S, O'Halloran P, Kingsley M. Integrated motivational interviewing and cognitive behaviour therapy for lifestyle mediators of overweight and obesity in community-dwelling adults: A systematic review and meta-analyses. BMC Public Health 2018;18(1):1160. doi: 10.1186/ s12889-018-6062-9.

16. Rubak S, Sandbaek A, Lauritzen T, Christensen B. Motivational interviewing: a systematic review and meta-analysis. Br J Gen Pract 2005;55(513):305-12.

correspondence ajgp@racgp.org.au 